\title{
Transparent, Polycrystalline Upconverting Nanoceramics: Towards 3-D Displays**
}

\author{
By Thomas R. Hinklin, Stephen C. Rand, and Richard M. Laine*
}

Although the concept of transparent, polycrystalline ceramics is now 40 years old, only recently has control of processing parameters been sufficient to produce photonic quality materials, Nd:YAG and Yb:Yttria lasers in particular. ${ }^{[1-7]}$ In all instances, average grain sizes (AGSs) in these fully dense materials are in the range 10-50 $\mu \mathrm{m}$. Furthermore, photonic quality transparency has only been achieved for materials with cubic crystal structures thereby avoiding scattering due to birefringence.

Recent work by Krell points to the possibility of also obtaining photonic transparency in materials with submicron AGSs, in $\alpha-\mathrm{Al}_{2} \mathrm{O}_{3}$ in particular. ${ }^{[8-10]}$ In principle, the smaller the final AGS and average defect size, the higher the expected transparency even for non-cubic crystal systems such as titanium doped sapphire $\left(0.5\right.$ at $\% \mathrm{Ti}^{3+}$ in $\left.\alpha-\mathrm{Al}_{2} \mathrm{O}_{3}\right)$ or ruby (0.5-3.0 at \% $\mathrm{Cr}^{3+}$ in $\left.\alpha-\mathrm{Al}_{2} \mathrm{O}_{3}\right)$. Access to such materials is best served by sources of high quality nano-oxides that permit lowtemperature densification without coincident grain growth.

If transparency can indeed be achieved with very fine-grained ceramics, the potential exists to create threedimensional emissive displays ${ }^{[11]}$ using the "inverted planetarium" concept described below. Transparent, upconverting phosphor pixels uniformly arrayed in thin walled spherical, cylindrical or even box shapes could provide 3-D displays in which color would be achieved by computer controlled rastoring of an IR laser (or lasers) in the interior of the display across the pixels at rates fast enough to generate 3-D images. Upconverting phosphors typically capture two IR photons (e.g., $960 \mathrm{~nm}$ ) and subsequently emit visible red, green and blue light depending on the phosphor, thus no visible beam is observed from a rastored IR source. ${ }^{[12-14]}$ Quantum efficiencies can be upwards of $5 \% .^{[14-16]}$

[*] Prof. R. M. Laine

Departments of Materials Science and Engineering University of Michigan

2300 Hayward St. Ann Arbor, MI 48109-2136 (USA)

E-mail: talsdad@umich.edu

Prof. S. C. Rand

Department of Electrical Engineering and Computer Science University of Michigan

2300 Hayward St. Ann Arbor, MI 48109-2136 (USA)

Dr. T. R. Hinklin

Sandia National Laboratories

Albuquerque, NM 87185-1315 (USA)

[**] The authors thank AFOSR (F49620-99-1-0158) as well as NSF DMR-0502715 and CISE-0531086 for support of this work. We also thank one reviewer for important contributions.
There is a significant body of work associated with upconversion in glass-ceramics and powders especially those made by sol-gel methods $;{ }^{[17-19]}$ however, there are no examples of upconversion from transparent polycrystalline ceramics in the literature. The approach described here complements recent work, in particular by the Downing group, ${ }^{[20]}$ to produce 3-D upconversion displays in solid transparent non-oxide glasses by overlapping of two laser of different wavelengths at a "voxel" to produce a specific color (RGB) dependent on the wavelengths of the lasers used and the rare- earth dopants using for upconversion. This technique was recently demonstrated for laminates of glasses each with a different phosphor (RGB). ${ }^{[20]}$

To realize inverted planetarium 3-D displays, several key processing methods must be brought to bear simultaneously. First, methods are needed to process uniformly arrayed pixels in thin green bodies. Each pixel should offer resolution of at least $50 \mu \mathrm{m}$ but preferably $<20 \mu \mathrm{m}$. Pixels must be separated from each other by $1-10 \mu \mathrm{m}$ by a non-emitting phase. ${ }^{[20]}$ Second, the pixels must be made transparent so they can be irradiated from the interior of the display with an IR laser. Third, a sufficiently powerful IR laser (or lasers) is (are) required whose light can be rastored at rates sufficient to illuminate the pixels for saturated output at the required refresh rate. We believe these processing and excitation issues are readily resolvable with current technology.

For example, Halloran et al. have developed a method of extruding uniformly ordered arrays of polymer binder/ceramic powder structures (pixels) within a matrix of a second ceramic/ binder powder structure that can be sintered to full density retaining original ordering and generating features as small as $10 \mu \mathrm{m}$ size uniformly separated by the second (i.e., nonemitting) phase by distances of $\leq 75 \mu \mathrm{m}$ as desired. ${ }^{[21-24]}$ The original green body can be "sliced" to give a sheet of ordered pixels in matrix of any desired thickness. Shaping in 3-D thereafter, followed by sintering to full density while maintaining that shape will be very difficult. Furthermore, current back-lit, large-screen displays use micromirrors to raster light sources across pixels on display surfaces. ${ }^{[11,22,25,26]}$ It appears that the greatest barrier to realizing such 3-D displays may be in creating small, transparent pixels of upconverting phosphors. Because pixel sizes should be as small as possible for optimal resolution, it seems that only transparent nanostructured matrices would provide the appropriate sizes, the required separation between pixels and sufficient mechanical strength to provide robust 3-D thin, hollow structures. The intent of this paper is to demonstrate processing of transparent 


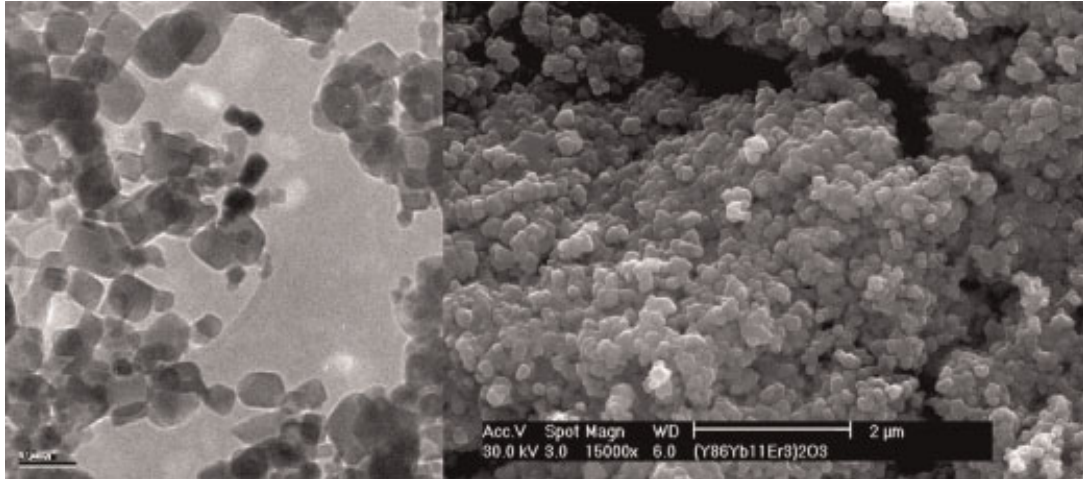

Figure 1. TEM of as produced and SEM of milled $\left(\mathrm{Y}_{0.86} \mathrm{Yb}_{0.11} \mathrm{Er}_{0.03}\right)_{2} \mathrm{O}_{3}$ powder suspension.

$70 \%$ depending on the wavelength, Figure 4. Furthermore, as seen in Figure 3b, on illumination with $980 \mathrm{~nm}$ light, through a mask, they upconvert this light to $662 \mathrm{~nm}$ emission in the form of an M. A Full emission spectra are presented in Figure 5.

The transmission behavior, although not perfect in the visible, is more than sufficient for our purposes given that we desired high absorption in the IR at $\approx 980 \mathrm{~nm}$ on the ${ }^{4} \mathrm{~F}_{7 / 2}-{ }^{4} \mathrm{~F}_{5 / 2}$ transitions of $\mathrm{Yb}^{3+}$ to optimize emission efficiencies. It is important to note that the IR transmission rivals that reported for large grained and single crystal materials such as yttria, sapphire, etc. as

polycrystalline upconverting phosphors that can serve as pixel materials for the proposed displays.

We have previously demonstrated that liquid-feed flame spray pyrolysis (LF-FSP) provides combinatorial access to a wide variety of single and mixed-metal oxide nanopowders ${ }^{[27,28]}$ including a novel hexagonal $\mathrm{Y}_{3} \mathrm{Al}_{5} \mathrm{O}_{12},{ }^{[29]}$ nano- $\alpha$ $\mathrm{Al}_{2} \mathrm{O}_{3},{ }^{[30]}$ abnormal spinel phases, ${ }^{[31]}$ and sets of upconverting phosphors. ${ }^{[32]}$ We have further reported novel laser action in doped versions of these nanopowders. ${ }^{[33]}$ We report here a method of processing selected $\mathrm{RE}: \mathrm{Yb}^{3+}: \mathrm{Y}_{2} \mathrm{O}_{3}$ upconverting phosphors to produce dense nanostructured materials that emit red and blue light, and are transparent suggesting that it may indeed be possible to develop a new form of 3-D display.

Figure 1 shows typical as-produced $\mathrm{Er}^{3+}$ doped nanopowders with average particle sizes of $<50 \mathrm{~nm}$. As with the majority of the powders produced by LF-FSP, these materials are single crystals that are primarily $(>90 \%)$ the cubic phase. These powders are readily processed (see below) using traditional dispersion techniques and consolidated using cold isostatic pressing to form green bodies with average densities of $60-63 \%$ of theoretical. Thereafter the powders are debindered by heating to $800^{\circ} \mathrm{C}$, vacuum sintered at $1350{ }^{\circ} \mathrm{C}$ or $1400^{\circ} \mathrm{C}$ for $5 \mathrm{~h}$ to densities $>95 \%$ and then HIPped at $1350{ }^{\circ} \mathrm{C}$ or $1400{ }^{\circ} \mathrm{C}$ at $140 \mathrm{MPa}$ for $3 \mathrm{~h}$. Subsequently, the pellets were air annealed for $3 \mathrm{~h}$ at $1250{ }^{\circ} \mathrm{C}$ producing the pellets shown in Figure 2 with typical microstructures as exemplified for the Er doped pellet in Figure 3a. The resulting pellets offer transparencies of up to

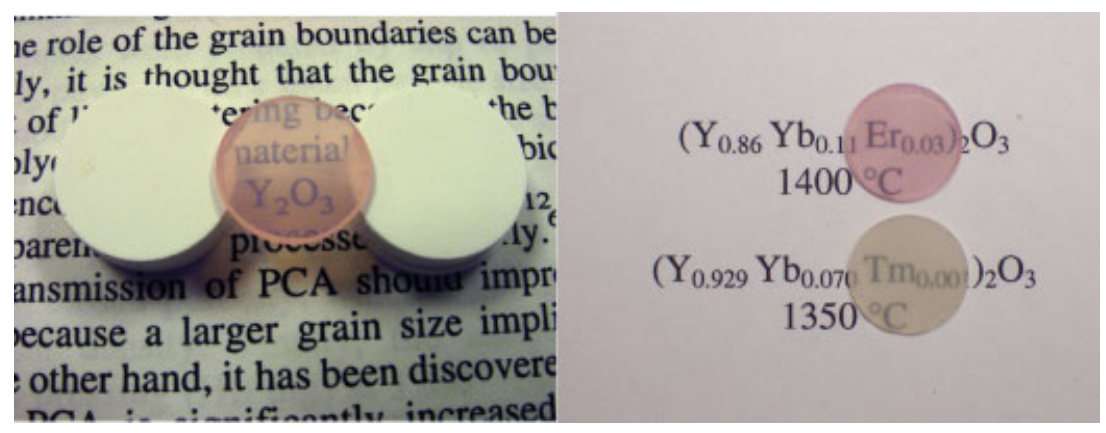

Figure 2. OM of $12.7 \times 1 \mathrm{~mm}$ red and blue upconverting transparent polycrystalline phosphors. shown in Figure 4. ${ }^{[34]}$ In Figure 4 additional (unused) absorption features are seen near 810, 660, and $540 \mathrm{~nm}$ resulting from transitions of $\mathrm{Er}^{3+}$ ions. ${ }^{[35,36]}$

The corresponding emission lines in Figure 5 resemble the narrow, Stark-split transitions of traditionally $\mathrm{Er}^{3+}$ and $\mathrm{Yb}^{3+}$ doped crystalline yttria. ${ }^{[32,35-38]}$

The use of crystalline rare earth oxides in display materials has been studied extensively over the past 20 years. ${ }^{[35-43]}$ Efficiencies are a key concern in emissive displays in rare earth materials, where multiple relaxation channels often exist. Not all channels result in light emission. Moreover there is abundant evidence in the literature that upconversion efficiency drops dramatically in rare earth nanophosphors compared to bulk solids. However, recently ${ }^{[42]}$ it was convincingly demonstrated that loss of efficiency in nanoparticles should be attributed predominantly to the incorporation of impurities such as $\mathrm{OH}$ during particle synthesis and to the use of hosts with high phonon frequencies. If present, impurities at the surfaces of particles are particularly effective at providing non-radiative relaxation channels for the emissive species. Fortunately, using LF-FSP powder synthesis and the processing approaches adopted here, it is feasible to prepare transparent ceramics where the transgrannular interfaces contain minimal amounts of $-\mathrm{OH}$, eliminating this loss channel. Additionally, if grain sizes can be maintained below $30 \mathrm{~nm}$, the increased density of low frequency phonon states known to arise purely from small particle sizes can be expected to reduce non-radiative losses further, obviating the need to select special hosts specifically for their low bulk phonon frequencies. ${ }^{[43]}$ In contrast, sol-gel derived materials will retain significant concentrations of $-\mathrm{OH}$ and any efforts to reduce their content by heating will likely lead to crystallization and loss of transparency.

This first step in realizing an appropriate pixel material; while successful, requires multiple additional steps before a true 3-D display system could be realized. First, the quality of the materials must be improved both in terms of transparency, grain sizes and 


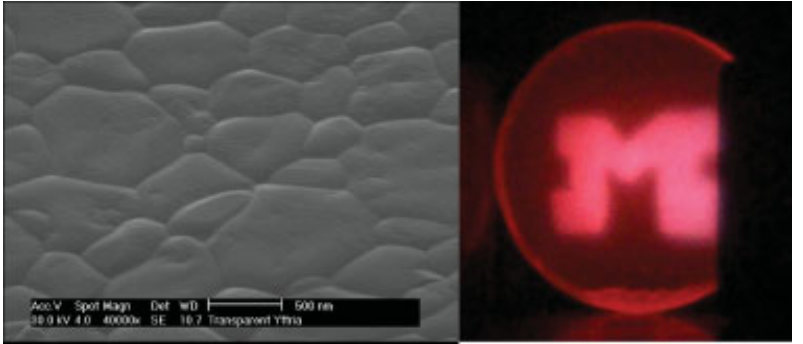

Figure 3. a) Microstructure of polished and thermally etched surface of HIPped Er doped material, $>98 \%$ dense showing average grain sizes of $400 \mathrm{~nm}$. b) Red emission (662 nm) on exposure to $980 \mathrm{~nm}$ light $(\phi=1 \mathrm{~cm}$, thickness $=1 \mathrm{~mm}$ )

emission wavelengths. Second, the extrusion process to generate pixilated structures must be explored and refined. Third, quantum efficiencies of these two photon processes must be optimized for both materials and a green upconverting phosphor, most likely one replacing $\mathrm{Er}^{3+}$ with $\mathrm{Tb}^{3+}$ must be developed. ${ }^{[37,38]}$ Fourth, although it is possible to produce RGB upconverting phosphors, as yet there are no indications that it is possible to access chromaticities that would have CIE coordinates that allow the production of true full color displays. Rather it may only be possible to create one or two color 3-D displays. Optimal performance can only be expected if it is possible to match the emission efficiencies for each phosphor component.

In the inverted planetarium approach, which will use thin pixels, transmission efficiencies are likely to be much less of a problem than in a system, as discussed above, that requires two lasers of complementary wavelengths to focus on a voxel. In the latter case, very high quality transparency is needed for laser light to traverse some significant fraction of a bulk solid to illuminate a particular voxel, without experiencing significant scattering. In addition, the resolution for this type of system may be limited by the ability to focus the laser beam. In contrast, in the inverted planetarium approach, each pixel is

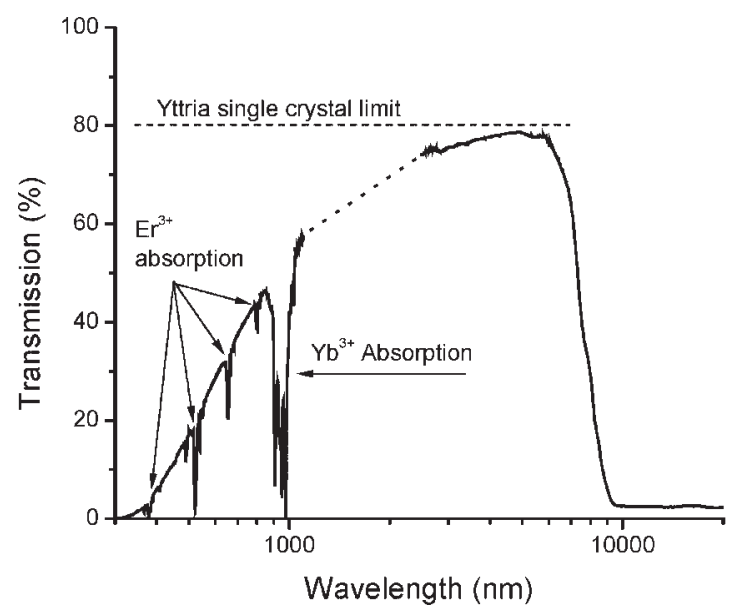

Figure 4. Transmission of polished, HIPped Er doped material, $1 \mathrm{~mm}$ thick [34].

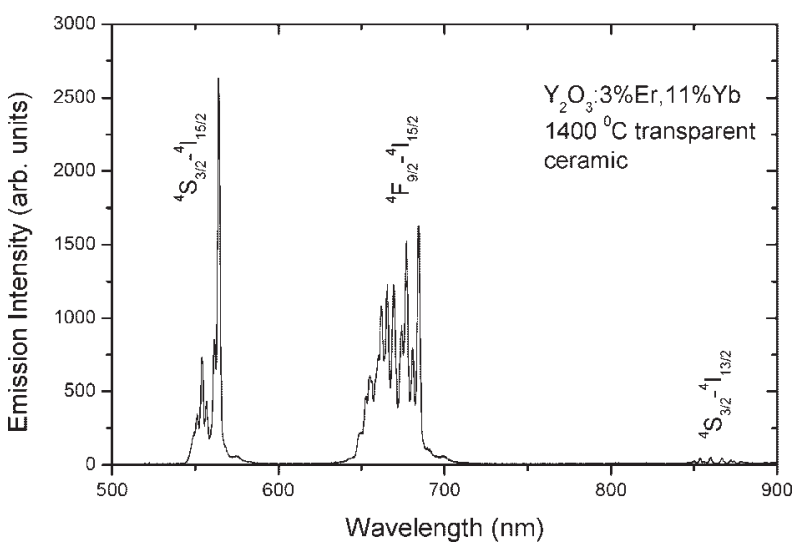

Figure 5. Emission behavior of polished, HIPped Er doped material, $1 \mathrm{~mm}$ thick [35].

defined by its diameter if it is assembled within an undoped surrounding matrix unresponsive to laser light. The ultimate thickness of the pixel will be defined by the efficiency with which the laser light is absorbed.

\section{Experimental}

Materials: Samples of upconverting phosphors were produced as described earlier [32, 44].

Liquid-Feed FSP: The apparatus used for LF-FSP consists of an aerosol generator, a combustion chamber and an electrostatic powder collection system described elsewhere in greater detail [24-28, 45]. The precursor solution is pumped through the aerosol generator at a rate adjusted to the ceramic yield of the solution: more concentrated (5 wt \% ceramic yield) solutions were pumped at $100 \mathrm{~mL} \mathrm{~min}^{-1}$ to avoid obtaining large particles $(200-1000 \mathrm{~nm})$. [24, 45] Solutions with lower ceramic yields were pumped at $400 \mathrm{~mL} \mathrm{m^{-1 }}$. The precursor solution was atomized with oxygen to form an aerosol and ignited by two methane/oxygen pilot torches, while the pressure in the system was kept at 20 psi. Combustion produces temperatures $>1500^{\circ} \mathrm{C} \mathrm{[24]} \mathrm{and}$ nanosized oxide powders are collected in electrostatic precipitators (ESP). The production rate was typically $\sim 50 \mathrm{~g} \mathrm{~h}^{-1}$.

Annealing Studies: Heat treatments were conducted in a Lindberg/ Blue box furnace (Model No. 58114, Watertown WI, controlled by a Eurotherm microprocessor, model No. 818P, Northing, England). Samples $(500 \mathrm{mg})$ of nanopowders were placed in alumina boats and heated to various temperatures from $850^{\circ} \mathrm{C}$ to $1650{ }^{\circ} \mathrm{C}$ at $20^{\circ} \mathrm{C} \mathrm{min}{ }^{-1}$ in air and maintained at temperature up to $12 \mathrm{~d}$. The resulting powders were cooled and analyzed as described below.

Powder Treatment and Compact Formation: The as-produced LF-FSP powders $(10 \mathrm{~g})$ were dispersed in $\mathrm{EtOH}(100 \mathrm{~mL})$ using a $1 / 2^{\prime \prime}$ ultrasonic horn (Sonics and Materials $600 \mathrm{VCX}$, Newtown, CT) at $40 \%$ power for $10 \mathrm{~min}$ in a Teflon beaker. The dispersion was allowed to settle for $48 \mathrm{~h}$ and the supernatant was extracted using a syringe without disturbing the sediment $(\approx 200 \mathrm{mg}$ ). The suspended powder in the syringe was further processed by adding bicene $(50 \mathrm{mg})$ and ball milled (24 h) using $3 \mathrm{~mm}$ zirconia media (Union Process, Akron, $\mathrm{OH}$ ) followed by the addition of $1000 \mathrm{D}(75 \mathrm{mg})$ and $8000 \mathrm{D}(75 \mathrm{mg})$ polyethylene glycol (Aldrich) and milled for an additional $24 \mathrm{~h}$.

After removal of the media, the dispersion was dried in a rotary evaporator at $150^{\circ} \mathrm{C}$. The dried powders were lightly ground in an alumina mortar and pestle and sieved to -325 mesh using nylon mesh in an acrylic holder. The granulated powder $(500 \mathrm{mg})$ was pressed 
(20 MPa) in a dual action $12 \mathrm{~mm}$ WC die followed by cold isostatic pressing (CIP) (200 MPa) (Autoclave Engineers, Erie, PA). The pressed pellets were subjected to a stepped binder burn out $\left(2{ }^{\circ} \mathrm{C} \mathrm{min}-1\right.$ to $800^{\circ} \mathrm{C}$ in air with 30 min holds every $100^{\circ} \mathrm{C}$ ).

Hot Isostatic Pressing: The binderless pellets were sintered in a $\mathrm{MoSi}_{2}$ tube furnace (Thermolyne 54500) in an alumina process tube $(99.9 \%$ Vesuvius McDanel, Beaver Falls, PA) under a mild vacuum $\left(-25^{\prime \prime} \mathrm{H}_{2} \mathrm{O}\right)$ to $1350^{\circ} \mathrm{C}$ or $1400^{\circ} \mathrm{C}$ for $5 \mathrm{~h}$ to achieve pore closure. The closed porosity pellets were then hot isostaticaly pressed (HIP) at $1350^{\circ} \mathrm{C}$ or $1400^{\circ} \mathrm{C}$ with $20 \mathrm{ksi}$ Ar for $3 \mathrm{~h}$. The HIPped pellets were then returned to stoichiometry by annealing in air $\left(1250^{\circ} \mathrm{C}, 3 \mathrm{~h}\right)$.

UV-VIS Measurement: UV-VIS transmission spectra were acquired using a Varian Cary 50 Bio UV-VIS spectrometer (Australia) from 1100 to $200 \mathrm{~nm}$. Background calibrations were performed by collecting the raw and blocked beam spectrum continuously in the range of $1100-200 \mathrm{~nm}$ with a scan resolution of $0.2 \mathrm{~nm}$ and rate of $1 \mathrm{~nm} \mathrm{~s}^{-1}$. Sample spectra were collected placing polished samples in the beam, held at the top and bottom edge with scotch tape.

Scanning Electron Microscopy (SEM): Micrographs were taken using a Phillips XL30 SEM. The powders were dispersed in distilled water using an ultrasonic horn (Vibra-cell, Sonics and Materials Inc.). Drops of the dispersed materials were deposited on an aluminum SEM stub and dried for $3 \mathrm{~h}$ on a hot plate. Samples were coated with a gold/ palladium coating by sputtering for 2 min, using a Technics Hummer VI sputtering system (Anatech Ltd.).

Transmission Electron Microscopy: Micrographs were taken on a JEOL 2100 XL. Samples were prepared using a carbon coated copper TEM grid (300 mesh). The powder was dispersed in distilled water using an ultrasonic horn, as above, and then a drop of the dispersed powder/water mixture was deposited on the grid. The grid was then dried for $4 \mathrm{~h}$ at $80^{\circ} \mathrm{C}$. The JEOL $2100 \mathrm{XL}$ was used with an accelerating voltage of $200 \mathrm{kV}$.

Received: May 21, 2007

Revised: September 12, 2007

[1] C. Greskovich, J. P. Cernoch, J. Appl. Phys. 1973, 44, 4599.

[2] A. Ikesue, T. Kinoshita, J. Am. Ceram. Soc. 1995, 78, 1033.

[3] I. Shoji, S. Kurimura, Y. Sato, T. Taira, A. Ikesue, K. Yoshida, Appl. Phys. Lett. 2000, 77, 939.

[4] A. Ikesue, Y. L. Aung, T. Taira, G. L. Messing, Annu. Rev. Mater. Res. 2006, 36, 397.

[5] A. Ikesue, Y. L. Aung, J. Am. Ceram. Soc. 2006, 89, 1936.

[6] J.-G. Li, T. Ikegami, J.-H. Lee, T. Mori, J. Am. Ceram. Soc. 2000, 83, 961.

[7] J. Lu, M. Prabhu, J. Song, C. Li, J. Xu, K. Ueda, A. A. Kaminskii, H. Yagi, T. Yanagitani, Appl. Phys. B 2000, 71, 469.

[8] A. Krell, P. Blank, H. Ma, T. Hutzler, R. Apetz, M. P. B. van Bruggen, J. Am. Ceram. Soc. 2003, 86, 12.

[9] R. Apetz, M. P. B. van Bruggen, J. Am. Ceram. Soc. 2003, 86, 480.

[10] A. Krell, J. Klimke, J. Am. Ceram. Soc. 2006, 89, 1985.

[11] A. Sullivan, IEEE Spectrum 2005, 42, 30.

[12] F. Auzel, Chem. Rev. 2004, 104, 139.

[13] A. M. Pires, S. Heer, H. U. Güdel, O. A. Serra, J. Fluoresc. 2006, 16, 461.

[14] K. Kuningas, T. Rantanen, T. Ukonaho, T. Lövgren, T. Soukka, Anal. Chem. 2005, 77, 7348
[15] R. H. Page, K. I. Schaffers, P. A. Waide, J. B. Tassano, S. A. Payne, W. F. Krupke, J. Opt. Soc. Am. B 1998, 15, 996.

[16] S. Redmond, S. C. Rand, Opt. Lett. 2003, 28, 173.

[17] A. Biswas, G. S. Maciel, C. S. Friend, P. N. Prasad, J. Non-Cryst. Solids 2003, 316, 393.

[18] F. Vetrone, J. C. Boyer, J. A. Capobianco, A. Speghini, M. Bettinelli, J. Phys. Chem. B 2003, 107, 1107.

[19] P. Y. Jia, J. Lin, M. Yu, Mater. Res. Bull. 2007, 42, 1556.

[20] a) E. A. Downing, US Patent 5684621, 1997. b) E. A. Downing, L. Hesselink, J. Ralston, R. A. Macfarlane, Science 1996, 273, 1185.

[21] L. Arbuthnot, J. Mendes, W. Sproull, M. Aguilera, B. Aitchison, C. King, G. Dolny, A. Ipri, F.-L. Hsueh, R. Steward, A. Ahmed, R Solanki, T. Keyser, S. Schlesinger, G. Becker, D. Kagey, M. Spitzer, SID' 96 Digest 1996, 374.

[22] S. Baskaran, J. W. Halloran, J. Am. Ceram. Soc. 1993, 76, 2217.

[23] D. Kovar, B. H. King, R. W. Trice, J. W. Halloran, J. Am. Ceram. Soc. 1997, 80, 2471.

[24] C. V. Hoy, A. Barda, M. Griffith, J. W. Halloran, J. Am. Ceram. Soc. 1998, $81,152$.

[25] L. J. Hornbeck, US Patent 4596992, 1986.

[26] L. J. Hornbeck, US Patent 4662746, 1987.

[27] T. Hinklin, B. Toury, C. Gervais, F. Babonneau, J. J. Gislason, R. W. Morton, R. M. Laine, Chem. Mater. 2004, 16, 21.

[28] J. Marchal, T. Hinklin, R. Baranwal, T. Johns, R. M. Laine, Chem Mater. 2004, 16, 822

[29] R. M. Laine, J. Marchal, H. J. Sun, X. Q. Pan, Adv. Mater. 2005, 17, 830.

[30] R. M. Laine, J. C. Marchal, H. P. Sun, X. Q. Pan, Nat. Mater. 2006, 5, 710.

[31] T. R. Hinklin, J. Azurdia, M. Kim, J. C. Marchal, S. Kumar, R. M Laine, Adv. Mater. DOI: 10.1002/adma.200702124.

[32] S. Li, H. Feindt, A. C. Sutorik, M. S. Baliat, R. M. Laine, R. S Niedbala, in: Nanoscience and Nanotechnology in Perspective, Tsinghua Press, Beijing 2002, pp. 221-233.

[33] G. Williams, S. C. Rand, T. Hinklin, R. M. Laine, Phys. Rev. A 2002, 65, 013807.

[34] R. L. Gentilman, Proc. SPIE-Int. Soc. Opt. Eng. 1986, 683, 2.

[35] P. A. Tanner, X. Zhou, F. Liu, J. Phys. Chem. B 2004, 108, 11521.

[36] G. H. Dieke, H. M. Crosswhite, Appl. Opt. 1963, 2, 675.

[37] B. Li, G. Williams, S. C. Rand, T. Hinklin, R. M. Laine, Opt. Lett. 2002, 27, 394.

[38] J. McKittrick, L. E. Shea, C. F. Bacalski, E. J. Bosze, Displays 1999, 19, 169.

[39] a) M. V. D. Vermelho, P. V. dos Santos, M. T. de Araújo, A. S. Gouveia-Neto, F. C. Cassanjes, S. J. L. Ribeiro, Y. Messaddeq, J. Lumin. 2003, 102-3, 762. b) L. D. Livanova, I. G. Saitkulov, A. L. Stolov, Sov. Phys. Solid State 1969, 11, 750.

[40] R. P. Rao, J. Electrochem. Soc. 1996, 143, 189.

[41] J. H. Zeng, J. Su, Z. H. Li, R. X. Yan, Y. D. Li, Adv. Mater. 2005, 17 , 2119.

[42] S. Heer, K. Kompe, H. U. Gudel, M. Haase, Adv. Mater. 2004, 16, 2102.

[43] X. L. Ruan, M. Kaviany, Phys. Rev. B 2006, 73, 155422.

[44] R. M. Laine, J. Marchal, S. Kim, J. Azurdia, M. Kim, Ceramic Nanomaterials and Nanotechnology III, Vol. 159, (Eds: S. Lu, M. Z. Hu, Y. Gogotsi), Ceramic Transactions, American Ceramic Society Westerville, OH 2004, pp. 18-24.

[45] A. T. Crumm, J. W. Halloran, J. Am. Ceram. Soc. 1998, 81, 1053. 